\title{
Takotsubo cardiomyopathy: a rare, but serious, complication of epileptic seizures
}

Cardiomiopatia de Takotsubo: uma complicação rara, mas grave, de crises epilépticas

João Rocha', Elsa Gonçalves², Catarina Vieira ${ }^{3}$, Fátima Almeida', João Pereira'

Study carried out at the Neurology Department of Hospital de Braga, Braga, Portugal.

${ }^{1}$ Neurology Department of Hospital de Braga, Braga, Portugal;

${ }^{2}$ Internal Medicine Department of Hospital de Santa Maria Maior, Barcelos, Portugal;

${ }^{3}$ Cardiology Department of Hospital de Braga, Braga, Portugal.

Correspondence: João Rocha; Neurology Department, Hospital de Braga; Sete Fontes, São Victor; 4710-243 Braga - Portugal; E-mail: joaomrocha@gmail.com Conflict of interest: There is no conflict of interest to declare.

Received 10 June 2012; Received in final form 12 September 2012; Accepted 19 September 2012.

Takotsubo cardiomyopathy (TKC) is a reversible, yet potentially fatal, syndrome triggered by stressful conditions, including seizures, with increasing recognition in clinical practice $^{1}$. We report a TKC in a patient with unexplained sinus tachycardia and troponin elevation after generalized seizures.

\section{CASE REPORT}

A 44 year-old woman presented with history of a subarachnoid haemorrhage five years ago, after a right posterior cerebral artery pseudoaneurysm rupture. Coil embolization was performed, complicated with a right cortico-subcortical 
temporo-occipital infarct with a slight left hemiparesis as a result. She was on acetylsalicylic acid $150 \mathrm{mg} /$ day, clopidogrel $75 \mathrm{mg} /$ day and prophylactic phenytoin $300 \mathrm{mg} /$ day.

Patient was admitted after four inaugural generalized tonic-clonic seizures (GTCS) that occurred in close succession during two hours. Consciousness was impaired between seizures, deeming it a clinical status epilepticus. She was assisted during a GTCS, sedated with midazolam perfusion and entubated, having ceased motor activity. After admission, she had no further seizures and regained conscious slowly after stopping midazolam, presenting a grade 4 left hemiparesis. Patient had infratherapeutic levels of phenytoin and started IV phenytoin. Electroencephalography (EEG) revealed pharmacological beta activity, but no epileptic activity. Brain computed tomography (CT) identified the right temporo-occipital infarction, overlapping previous exams. Seizures were interpreted as symptomatic due to the cortical lesion and infratherapeutic levels of phenytoin.

After recovery, she was apyretic, normotensive, but tachycardic (110-130 bpm). She had no cardiac or respiratory complaints. Electrocardiogram (ECG) showed sinus tachycardia and 12 hours latter T wave inversion in V1-V3 leads (Figs 1A and B). Serum troponin was $6,48 \mathrm{ng} / \mathrm{mL}$. Transthoracic echocardiogray demonstrated mild depression of left ventricle systolic function, hypokinesia of apical segments with hypercontractility of the basal ones. These kinetic changes were confirmed by left ventriculography (Fig 2). Coronarography was normal, establishing the diagnosis of TKC. She continued treatment with ramipril and double antiplatelet therapy, previously prescribed because of her endovascular intervention, with clinical improvement.

\section{DISCUSSION}

Takotsubo cardiomyopathy is a reversible dysfunction of the left ventricle in the absence of coronary disease, probably related to excessive catecholamine release due to sympathetic hyperactivity induced by stressful factors ${ }^{2}$.

Patients present signs of ventricular dysfunction or only sinus tachycardia. Chest pain is infrequent in post-epileptic $\mathrm{TKC}^{3}$. Troponin levels are elevated in the absence of coronary disease, and ECG may present with Q waves, ST segment elevation or $\mathrm{T}$ wave inversion ${ }^{2}$. Treatment is supportive and mortality is as high as $8 \%^{3}$.

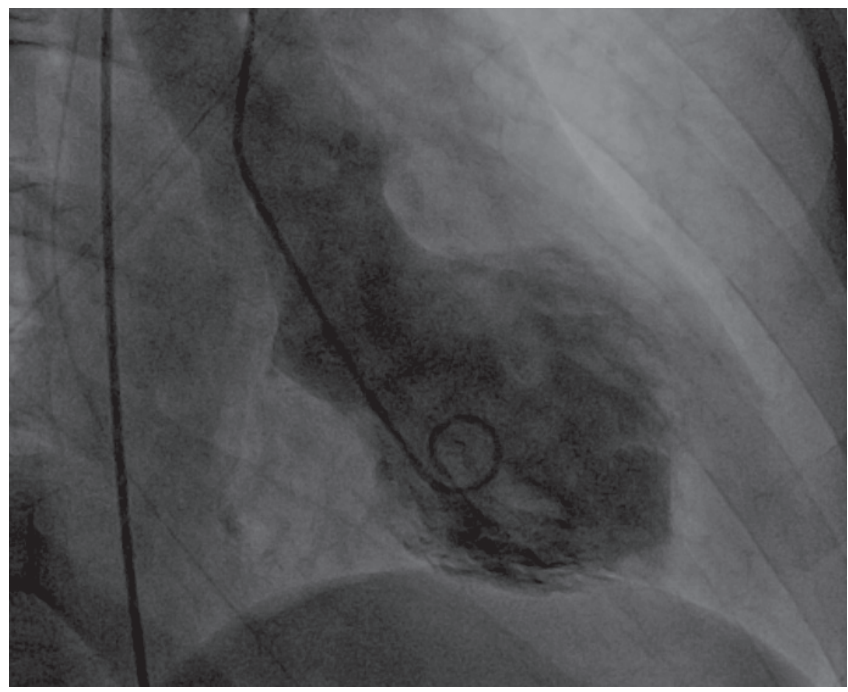

Fig 2. Ventriculography with typical left ventricular apical ballooning - hypocontractility of the apical segments and hypercontractility of the basal segments.

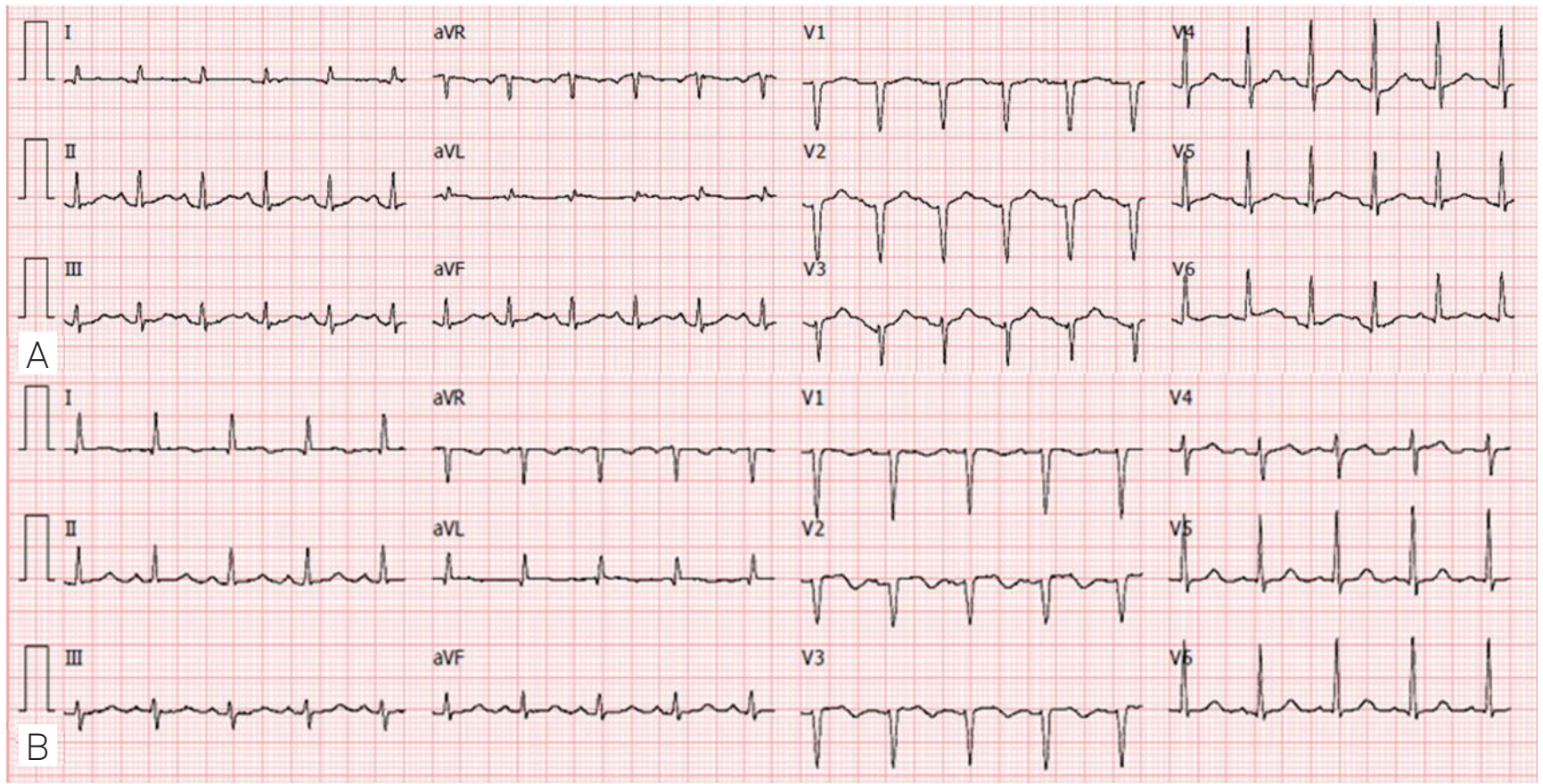

Fig 1. Electrocardiogram (ECG). (A) Admission ECG with sinus tachycardia; (B) control ECG with T wave inversion (V1-V3). 
Association between TKC and epileptic seizures (focal or generalised) is increasingly reported, and seizures may be the triggering factor of catecholamine release that promotes the cardiotoxic response. Focal epileptic activity of the temporal lobe may cause autonomic dysfunction that promotes cardiac damage 4 . The majority of post-epileptic TKC cases are women, mean age 62.7 years. Epilepsy etiology may be varied ${ }^{1}$.
Cardiac complications are one of the main causes of mortality in epilepsy ${ }^{5}$. Incidence of TKC after epileptic seizures is unknown and could be related to cardiac death in epileptic patients ${ }^{1}$. The authors highlight the importance of suspecting TKC in patients with seizures and signs of cardiac dysfunction as subtle as sinus tachycardia. Timely recognition of this complication is important to provide adequate supportive care.

\section{References}

1. Dupuis M, van Rijckevorsel K, Evrard F, Dubuisson N, Dupuis F, Van Robays P. Takotsubo syndrome (TKS): a possible mechanism of sudden unexplained death in epilepsy (SUDEP). Seizure 2012;21:51-54.

2. Chockalingam A, Mehra A, Dorairajan S, Dellsperger KC. Acute left ventricular dysfunction in the critically ill. Chest 2010;138:198-207.

3. Stöllberger C, Wegner C, Finsterer J. Seizure-associated Takotsubo cardiomyopathy. Epilepsia 2011;52:160-167.
4. Naganuma M, Isoda $K$, Ishizaki M, Ito K, Hirano T, Uchino M. Epilepsy and Takotsubo cardiomyopathy: a case report. Intern Med 2011;50:2397-2399.

5. Rodríguez de Antonio LA, Aguilar-Amat Prior MJ, Iváñez-Mora V, DíezTejedor E. Miocardiopatía de Takotsubo como complicación de un estado epiléptico. Rev Neurol 2011;53:673-676. 